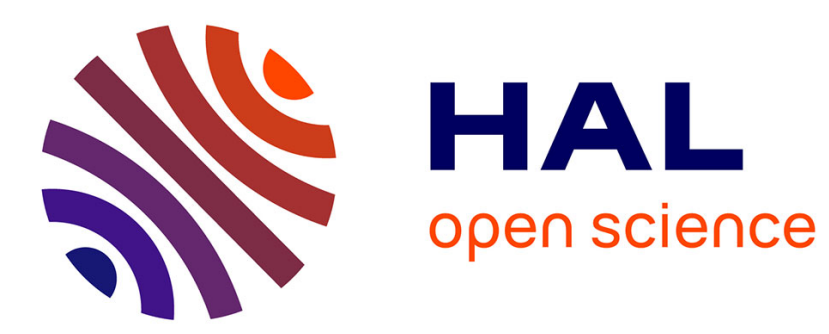

\title{
Cross-dock distribution and operation planning for overseas delivery consolidation: A case study in the automotive industry
}

Christian Serrano, Xavier Delorme, Alexandre Dolgui

\section{To cite this version:}

Christian Serrano, Xavier Delorme, Alexandre Dolgui. Cross-dock distribution and operation planning for overseas delivery consolidation: A case study in the automotive industry. CIRP Journal of Manufacturing Science and Technology, 2021, 33, pp.71-81. 10.1016/j.cirpj.2021.02.007 . hal-03176631

\section{HAL Id: hal-03176631 \\ https://hal.science/hal-03176631}

Submitted on 22 Mar 2021

HAL is a multi-disciplinary open access archive for the deposit and dissemination of scientific research documents, whether they are published or not. The documents may come from teaching and research institutions in France or abroad, or from public or private research centers.
L'archive ouverte pluridisciplinaire HAL, est destinée au dépôt et à la diffusion de documents scientifiques de niveau recherche, publiés ou non, émanant des établissements d'enseignement et de recherche français ou étrangers, des laboratoires publics ou privés. 


\title{
Cross-dock distribution and operation planning for overseas delivery consolidation: a case study in the automotive industry
}

\author{
Christian Serrano ${ }^{1}$, Xavier Delorme ${ }^{2}$, Alexandre Dolgui ${ }^{3}$ \\ ${ }^{1}$ Renault, France \\ christian.serrano@renault.com \\ ${ }^{2}$ Ecole des Mines de Saint-Etienne, LIMOS-CNRS, France \\ delorme@emse.fr \\ ${ }^{3}$ IMT Atlantique, LS2N-CNRS, France \\ alexandre.dolgui@mines-nantes.fr
}

\begin{abstract}
Christian Serrano
IT/Process Engineer

Renault SAS

1 avenue du Golf

78084 Guyancourt, France been applied to solve the associated models.

\author{
Xavier Delorme \\ Full professor \\ Henri Fayol Institute \\ Ecole des Mines de Saint-Etienne \\ 158 Cours Fauriel \\ 42023 Saint-Etienne Cedex, France
}

Industrial Engineering Master's degree in 2012 at Ecole Nationale d'Ingénieurs de Metz, his research focused on reverse logistics network design and was completed in partnership with the Public Research Centre Henri Tudor. Since 2013, he obtained his PhD degree at Ecole Nationale Supérieure des Mines de Saint-Etienne and at Renault's Supply Chain Direction. $\mathrm{PhD}$ project concerned Renault cross-docking platforms and is related mainly to the following research fields: distribution planning, operation scheduling and supply chain network optimization. In the first stage, Operation Research methods have

Full Professor within the LIMOS Lab. at the École Nationale Supérieure des Mines de Saint-Etienne. His works seek to find mathematic models and algorithms to support Decision-Making in Industry, mainly using optimization methods from Operations Research. Therefore, they are related to several scientific areas such as Industrial Engineering, Mathematics or Computer Science. He is currently co-chair of the Organizing Committee of the Congress of the French National Society of Operations Research and Decision Science ROADEF 2011.

\section{Alexandre Dolgui \\ Distinguished professor and Head \\ IMT Atlantique, LS2N-CNRS \\ La Chantrerie, 4, rue Alfred Kastler \\ 44307 Nantes, France}

Fellow of IISE, Distinguished Professor (Full Professor of Exceptional Class) and Head of Department at IMT Atlantique, France. His research focuses on manufacturing line design, production planning and supply chain optimization. His main results are based on the exact mathematical programming methods and their intelligent coupling with heuristics and metaheuristics algorithms. He is the Editor-in-Chief of the International Journal of Production Research, an Area Editor of Computers \& Industrial Engineering, past Associate Editor of International Journal of Systems Science (2005-2008), IEEE Transactions on Industrial Informatics (2006-2009) and Omega-the International Journal of Management Science (20092012), consulting Editor of the International Journal of Systems Science (2009- ).

C. Serrano, X. Delorme, A. Dolgui. Cross-dock distribution and operation planning for overseas delivery consolidation: a case study in the automotive industry, CIRP Journal of Manufacturing Science and Technology, vol. 33, 2021, pp. 71-81. 


\title{
Cross-dock distribution and operation planning for overseas delivery consolidation: a case study in the automotive industry
}

\begin{abstract}
One of the strategic objectives of supply chains in the automotive industry is the development of international sourcing. Renault works with a global network of cross-docking platforms to link distant assembly plants with first-tier suppliers. These platforms act both as information and physical consolidation points. At shop-floor, inland deliveries are received, sorted, repacked (if needed) and loaded onto containers for overseas transportation. Distribution and operation planning are key activities in such a cross-dock platform but despite its interdependency, current research considers them separately. This paper presents a detailed analysis of Renault cross-dock platforms called ILN (International Logistics Networks), their planning process and physical flows. An integer linear programming model to plan jointly the distribution and shop-floor operations in a cross-dock platform of Renault is developed. The objective is to minimize total cost composed of transportation cost (inbound and outbound), cost of internal resources and storage cost. Numerical offline tests of the model with CPLEX, based on real data for a number of past periods, have showed a $13 \%$ reduction of total cost. These encouraging tests confirm both the ability of the proposed approach to deal with real-size instances and the potential gains which can be obtained by considering decision related to distribution and planning together. Taking into account these results, the part of model concerning inbound logistics was integrated in the planning system used in a Renault ILN. The results of the first exploitation period have shown a reduction of $20 \%$ of inbound transportation cost comparing with the previous period without increasing the other costs.
\end{abstract}

Keywords - Cross-dock; Distribution and operation planning; Integer linear program; Optimization; Automotive industry.

\section{INTRODUCTION}

Once major carmakers started to reach almost every market in the globe, automotive industry was pushed to internationalize its activity in order to maintain competitiveness. Economic factors such as the boom of emerging markets or the financial crisis of 2008/09, created the circumstances to back up this kind of strategy. Because of it, most car manufacturers decided to set up industrial facilities outside their home countries in a growing tendency, as many companies are currently investing all around the world (Cârstea, 2013). In such a globalized 
context, oversea logistic flows of Renault have drastically increased, in particular the export of individual parts (Renault, 2016). The same tendency revealed in other automotive groups (Fleischmann 2006; Itoh and Guerrero, 2020).

Since this activity entails a major logistics challenge in terms of lead time, quality and cost, as several other automotive firms (Carbone and De Martino, 2003; Frigant and Martin, 2014), Renault creates cross-dock platforms to consolidate and deliver components. These platforms, Renault calls them International Logistics Networks (ILN), are only used for merging components for international distant deliveries. No cross-dock for inbound logistics is used. The components are received via inbound logistics, repackaged for transportation by boats and delivered to overseas plants. The main idea of cross-docking strategy here is to transfer incoming deliveries to outgoing vehicles, with almost no storage or treatment in between.

One good example of the situation explained in Renault (2016). Present in 128 countries, Renault's international development strategy has led to a rise of sales outside of the EU, from $23 \%$ in 2004 to $46 \%$ in 2014 (peak of 51\% in 2013), with Brazil and Russia as key markets of the group. Concerning industrial facilities, by the end of 2013, 8 out of 18 Renault assembly plants were located outside of Europe, accounting for 52\% of finished vehicles production. However, almost $80 \%$ of engines and gearboxes were manufactured within EU countries. Moreover, many suppliers are still located in this region, which means a significant amount of components must be exported to distant industrial sites. To do so, Renault relies on a set of nine multi-modal export-oriented platforms, called ILNs (International Logistics Networks). These platforms link overseas industrial sites (which will be referred to also as customers) with inland suppliers. Four of them are located in Europe and represented $87 \%$ of Renault's exported volume of individual parts in 2013 (3.5 million $\left.\mathrm{m}^{3}\right)$. 
From figure 1 it can be noticed that a Renault ILN acts both as information and physical consolidation point. Once customers' delivery orders are received, distribution and operation planning are carried out. Based on this process, orders are generated and transmitted to suppliers. Upon arrival at the ILN, deliveries are unloaded from inbound trucks, then sorted, repacked (10-20\% of total volume), moved across the facility and finally loaded onto outbound containers for overseas shipping. As it is possible to observe here, ILN platforms have a double purpose: on the economic level, Renault seeks to reduce overseas transportation costs by consolidating components, on the operational level, this configuration simplifies distant supply management for suppliers since they will not have to deal, each separately, with several aspects such as lead times, customs, time zones, language, cultural environment, etc.

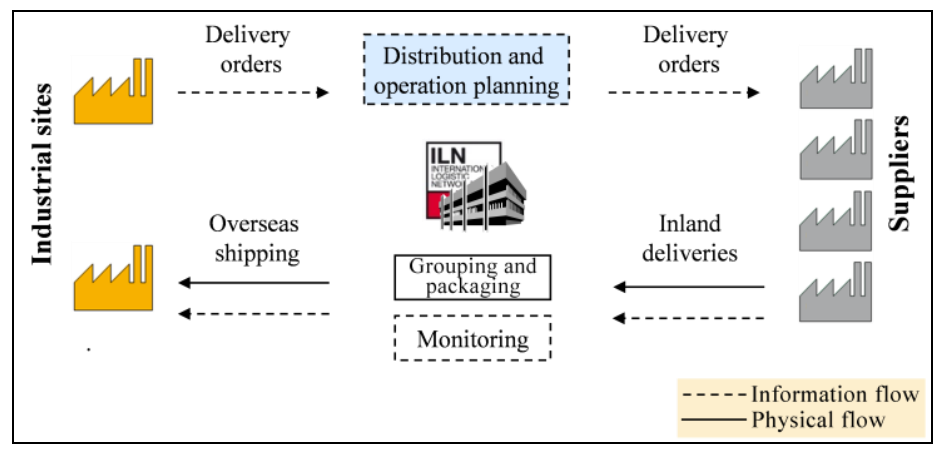

Figure 1. Logistics network of a Renault ILN platform

Based on the analysis of current processes of ILN platforms, this article proposes an alternative method to improve the planning process. In particular, by establishing a better transportation costs assessment and a more accurate daily workload allocation. The purpose of this research is twofold. On the one hand, a specific industrial situation is presented and improved; with still encouraging perspectives in the short term. On the other hand, two research fields, which are mostly treated individually in literature, are brought together: distribution and operation planning in a cross-dock centre. 
The rest of paper is organized as follows: in section 2, Renault's ILN information and physical flows are explained in detail; their impact on performance, improvement opportunities, as well as the overall scope of this work are discussed. Accordingly, a literature review and the problem definition are presented in section 3. Afterwards, in section 4, the suggested integer linear programming model and results of numerical experiments are reported with a focus on the methodology. The industrial implementation of a simplified version of the model, which concerns only inbound transportation, is presented in section 5 . Finally, a discussion on results of this research is presented in section 6 and the conclusion, with both industrial and research perspectives, is given in section 7 .

\section{RENAULT ILN OPERATION MODE AND PROBLEM DEFINITION}

Based on figure 1, this section aims to explain both, information and physical flows at Renault ILNs. A related performance analysis, based on a 5-month period study in (Serrano, 2017) of one Renault ILN, is presented as well, to assess some improvement opportunities and describe the scope of this work.

\subsection{Information flow: distribution and operation planning}

Figure 2 presents an example of delivery plan for a Renault ILN and a given component. Such a plan is established once a week for all components. The first step is the reception of the customers' orders. For week 11, for example, on Monday it is demanded a quantity of 20, on Tuesday 35 and so on. Second, the shipment schedule is generated based on the corresponding customer lead time, this time includes the time of transportation between the ILN platform and customers (the time from the cargo ship departure to arrival). Moreover, a day of transit at the ILN shop-floor is added to every component to obtain, as a result, the due dates for suppliers of ILN. In the next step, the planning system verifies the inbound transportation days used correspond to those contracted with suppliers and thus the supplier 
delivery schedules are generated. Figure 2 illustrates how release dates are calculated for ILN and ILN suppliers. In the example shown in figure 2, the contracted delivery days for the corresponding supplier are Monday and Wednesday. Hence, the quantities planned for both Monday and Tuesday will be ordered for Monday (20+35) and the quantities planned for Wednesday, Thursday and Friday will be ordered for Wednesday $(20+0+70)$. Finally, supplier lead time is calculated to obtain the release date for the supplier. In the example in figure 2, the supplier lead time is equal to one week (5 days). Then, daily schedule is inferred from the obtained plan. Based on this information, the workload for each shop-floor activity is calculated resulting in the estimation of the total amount of resources needed for the whole week. Figure 2 illustrates how for a component taking into account the known days for ship departure and arrival as well as other elements of customer lead time, one day ILN lead time and taking into account the contractual day for delivery of components by a supplier and the supplier lead time, the release dates for the supplier and ILN are calculated. In the figure there is no information on how the transportation is executed. In practice, it is executed in a smooth manner taking into account the capacity of transport and the fact that the inventory cost in the harbour is already included in the total transportation cost, so no necessity for Renault to minimize the inventory and inventory cost in harbour.

\begin{tabular}{|c|c|c|c|c|c|c|c|c|c|c|c|c|c|c|c|c|c|c|c|c|c|c|c|c|c|c|}
\hline \multirow{2}{*}{ Period } & \multicolumn{5}{|c|}{ W1 } & \multicolumn{5}{|c|}{ W2 } & \multicolumn{5}{|c|}{ W3 } & \multicolumn{6}{|c|}{ W10 } & \multicolumn{5}{|c|}{ W11 } \\
\hline & $\mathbf{M}$ & $\mathbf{T}$ & W & $\mathbf{T}$ & $\mathbf{F}$ & $\mathbf{M}$ & $\mathbf{T}$ & W & $\mathbf{T}$ & $\mathbf{F}$ & $\mathbf{M}$ & $\mathbf{T}$ & $\mathbf{w}$ & $\mathbf{T}$ & $\mathbf{F}$ & & $\mathbf{M}$ & $\mathbf{T}$ & W & $\mathbf{T}$ & F & $\mathbf{M}$ & $\mathbf{T}$ & W & $\mathbf{T}$ & $\mathbf{F}$ \\
\hline Due date & & & & & & & & & & & & & & & & & & & & & & 20 & 35 & 20 & o & 70 \\
\hline Cargo ship arrival & & & & & & & & & & & & & & & & & & & $\mathbf{x}$ & & & & & & & \\
\hline Cargo ship departure & & & & & & & & & & & & & & $\mathbf{x}$ & & & & & & & & & & & & \\
\hline $\begin{array}{l}\begin{array}{l}\text { Ready for shipment to } \\
\text { harbour }\end{array} \\
\end{array}$ & & & & & & & 20 & 35 & 20 & 0 & 70 & & & & & $\cdots$ & & & & & & & & & & \\
\hline Processing/packaging & & & & & & 20 & 35 & 20 & 0 & 70 & & & & & & & & & & & & & & & & \\
\hline $\begin{array}{l}\text { Delivery from } \\
\text { supplier }\end{array}$ & & & & & & 55 & 0 & 90 & $\mathbf{0}$ & 0 & & & & & & & & & & & & & & & & \\
\hline S/order & $\mathbf{x}$ & & & & & & & & & & & & & & & & & & & & & & & & & \\
\hline
\end{tabular}

Figure 2. Example of distribution and operation planning at Renault ILN for one component.

\subsection{Material flow: shop-floor operation}


Figure 3 resumes the material flows and processing activities in a Renault ILN. Once a truck arrives at the ILN it is assigned to an inbound door. From this point, packages are unloaded and placed in a first staging zone, where a labelling activity is carried out. Next, if repackaging is needed, they are moved to an intermediate workshop. If not, they go directly to the outbound staging zone, where they are sorted by customer. From this point, packages are loaded onto containers and finally, containers are transported to a nearby harbour for overseas shipment. Despite a daily flow of containers between the ILN and the harbour, in most cases there is only one cargo ship departure per week, per destination. The latter means that all components issued from the same week, will be delivered at the same time at customers' sites. This is a Renault rule which takes into account transport constraints of two types: it is impossible to have a ship every day (too costly) but at the same time the deliveries by trucks from ILN to harbour have to be processed more often (sometimes even daily) due to volume/capacity constraints.

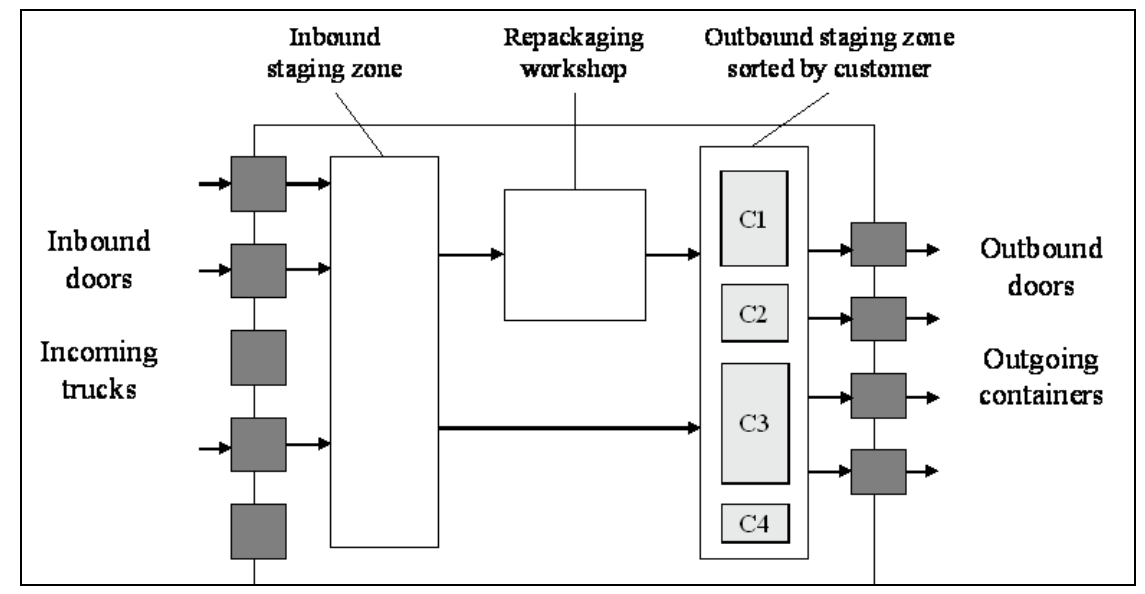

Figure 3. Renault ILN's physical flow scheme.

\subsection{Cost drivers and impact of the current planning process on performance}

A 5-month period was studied at one Renault ILN. The considered platform receives around 150 trucks per week and exports around 100 containers per week. At the shop-floor $(10,000$ $\mathrm{m}^{2}$ ) there are 5 inbound doors and 4 outbound doors and a team of around 30 people performs 
the cargo unloading, repacking, moving and loading activities. Three main operational cost drivers were identified, each one related to one level of the supply chain: truck filling rate (for inbound trucks), daily workload (internal resources, e.g. operators) and container filling rate (outbound deliveries). Storage is allowed at the platform, but since the warehouse is big enough for the maximum possible stock, Renault decided to not consider the internal stock as an operational cost driver. Moreover, as explained in subsection 2.1, the main and only parameter used by Renault planning software to calculate supplier, ILN processing and delivery schedules at the delivery planning step is customers' daily due date. Transportation filling rates (for inbound trucks and outbound containers) and shop-floor workload (internal resources and storage) are not taken into account.

In reality, on the field, good results on container filling rate were observed, with an average value close to $85 \%$. This can be explained by the fact that the shipment schedule is not completely respected. At shop-floor, in order to improve the container filling rate, packages may be retained at the staging zones, on the condition that the cargo ship departure date is respected, i.e. the daily schedule can be violated in order to increase container filling rate if the final constraint on the ship departure date is respected. The latter avoids any negative impact on customer service level. Concerning internal workload level and inbound truck filling rate, the situation becomes less performant. On the one hand, it was noticed high daily workload variability, which results in a non-optimal weekly resources assessment, on the other hand, even if the inbound transportation pre-contracted plan is respected, a low truck filling rate (52\% in average) is observed in reality. Both situations are the consequence of the delivery schedule. From suppliers' point of view, there is no flexibility versus given delivery dates and since they are not responsible for inbound transportation, a low truck filling rate is not their concern. 


\subsection{Improvement opportunities and work scope}

To sum up the previous description, it is noticeable that the current planning process at Renault ILN does not include its main operational cost drivers. Results on the field study showed an important impact on global performance. Moreover, there is a gap between what is planned and what is actually carried out at shop-floor, due to the time differences between the planned delivery days and the actual cargo ship departure day, whereas this decoupling point could actually be used to optimize the network flows and the internal operation planning. Table 1 sums up the previous description. Consequently, an alternative method for delivery and operation planning at a cross-dock, based on a Renault ILN configuration, integrating its main parameters, cost drivers and constraints is proposed in this paper.

\begin{tabular}{|l|l|l|l|}
\hline \multicolumn{2}{|c|}{ Planning process } & \multicolumn{1}{c|}{$\begin{array}{c}\text { Theoretical physical } \\
\text { flows }\end{array}$} & \multicolumn{1}{c|}{$\begin{array}{c}\text { Observed on field study } \\
\text { (performance) }\end{array}$} \\
\hline Shipment & $\begin{array}{l}\text { Customer orders received weekly, } \\
\text { with daily demands. }\end{array}$ & $\begin{array}{l}\text { Containers sent daily to } \\
\text { harbour. Cargo ship } \\
\text { departure once a week } \\
\text { weekly deliveries at } \\
\text { customers'. }\end{array}$ & $\begin{array}{l}\text { Good CFR (container filling rate): } \\
\text { 85\%. Flexibility on shipment } \\
\text { schedule due to the weekly cargo } \\
\text { ship depart. No impact on service } \\
\text { level. }\end{array}$ \\
\hline $\begin{array}{l}\text { Grouping } \\
\text { and } \\
\text { packaging }\end{array}$ & $\begin{array}{l}\text { Inferred from the shipment schedule. } \\
\text { Daily treatment. }\end{array}$ & Daily treatment. & $\begin{array}{l}\text { High variability on daily workload } \\
\text { (especially on unloading). } \\
\text { Relatively high storage level. }\end{array}$ \\
\hline Delivery & $\begin{array}{l}\text { Inferred from treatment schedule and } \\
\text { consolidated regarding the inbound } \\
\text { transportation plan. Supplier orders } \\
\text { sent weekly, with daily demands. }\end{array}$ & $\begin{array}{l}\text { Daily deliveries from } \\
\text { suppliers. }\end{array}$ & $\begin{array}{l}\text { Low TFR (truck filling rate): } 52 \% . \\
\text { No flexibility on delivery schedule. } \\
\text { Suppliers are not concerned with } \\
\text { transportation costs. }\end{array}$ \\
\hline
\end{tabular}

Table 1. Comparison of operation frequency between the planning process and the physical flows.

\section{ANALYSE OF RELATED LITERATURE}

Nowadays, in a globalized industrial environment, supply chain performance is crucial to maintain competitiveness since companies must assure the delivery of products at the right time, with the desired quality level and at the minimum cost. A relatively new strategy to support this objective is cross-docking. A cross dock centre is an intermediate point in a supply chain, in which products from incoming trucks are unloaded, sorted, moved across and 
ultimately loaded onto outgoing trucks. According to Saddle Creek Logistics Services Report (2011), this logistic solution may result in a reduction of lead times, a decrease of stock levels and economies in transportation. More and more enterprises use cross-docks and the academic literature is also rich, see the state of the art presentations (Boysen and Fliedner, 2010; Theophilus et al., 2020). Nevertheless, since few authors present an implementation of their work in a cross-dock centre, a gap between industry practice and current research is observed (Ladier, 2016; Theophilus et al., 2020). Based on Van Bell et al.'s (2012) classification by decisional level, main study subjects concerning cross-docking are:

- Strategical: geographic location and internal layout.

- Tactical: distribution network planning and vehicle routing (inbound and outbound).

- Operational: operation planning: truck scheduling (inbound and outbound), dock door assignment (inbound and outbound), shop-floor operation scheduling

Main research on strategic decision deals with supply chain design problems, considering one or more cross-docking centres. The main objective is to define network flows including facility location-allocation decisions. Shop-floor layout has also received important attention. The size, the shape and the number of doors impact the internal activities and related models seek to maximize cross-dock performance in terms of travel distances, number of touches and workload. For a review of articles dealing with described subjects, refer to Van Bell et al. (2012). Since our research considers only cross-dock platforms that are already up-andrunning, strategic issues are left out of scope. Vehicle routing for both inbound and outbound flows for ILN can be neglected. The vehicle routing for inbound flows is considered as a given input (based on Renault inbound transportation pre-contracted plan). The vehicle routing for outbound flow is relatively simple. Thus, our study focuses on two fields: distribution and operation planning in cross-docking. Related literature will be presented next.

\subsection{Distribution planning}


Decisions related to distribution network planning within cross-docking can be considered as an extension of the shipment consolidation problem, which studies a distribution network consisting of a set of supply, transhipment and demand nodes. Product flow quantities, number of facilities and number of trucks are the common decision variables. Different types of constraints can be contemplated like time windows, capacity (storage, treatment, and transportation), direct link between suppliers and customers, among others.

Miao et al. (2009) presented a model that seeks to determine product flow quantities and allocation through cross-docks centres including fixed-schedule transportation constraints and tardiness costs in a distribution network. The authors propose a genetic algorithm to minimize total costs (transportation, inventory holding and penalty) and compare their results with CPLEX performance. Chen et al. (2006) studied a cross-docking network for which they determine a distribution plan based on expected supplies and demands. Their model minimizes inventory handling costs and transportation costs, satisfying storage capacity and time windows constraints. A set of heuristics methods is proposed and tested, providing quality solutions in realistic timescales. It is hard to compare them because they were developed for different contexts and with different assumptions; nevertheless, the main ideas are very useful for any related problem.

An ant colony optimization algorithm which aims to minimize total shipping cost in a crossdocking network is proposed by Musa et al. (2010). The number of trucks and product quantities are determined for each link of the network. Storage is not allowed and direct transportation between suppliers and customers is considered. Results from numerical experiments showed a significant cost reduction and outperformed Branch-and-Bound methods. 
Ma et al. (2011) studied a global optimization problem in a cross-docking network. A twostage heuristic algorithm which defines TL (truck load) and LTL (less-than-truckload) transportation planning is proposed to determine the quantity of products shipped on each arc of the distribution network. The objective of the model is to minimize transportation and inventory costs. Time windows constraints and truck setup costs are included. Computational experiments showed efficiency in terms of runtimes and solution quality.

A two-manufacturer distribution network with cross-docking centres is considered by Gümüs and Bookbinder (2004). They proposed a mixed integer linear programming model, based on the uncapacitated facility location problem, which seeks to minimize fixed facility, transportation and inventory costs. The latter is considered only at supply and demand nodes. Several numerical experiments were conducted using LINGO and CPLEX software and due to the problem's complexity, they proposed to decompose it into a set of simpler subproblems.

Soleimaninanadegany et al. (2017) have proposed a genetic algorithm to solve the problem of allocating products to cross-dock or warehouse. The processing costs, customer demand, cross-dock and warehouse capacities and many specific constraints are taken into account. Bienert et al. (2017) study the impact of split deliveries in crossdocking situations, and their consequences on inventory performances for distribution centres and customer service level.

Meysam Mousavi and Tavakkoli-Moghaddam (2013) considered both location and routing scheduling problems. A two-stage mixed-integer programming model for the location of cross-docks and vehicle routing scheduling was developed for retailer distribution networks. Efficient metaheuristics were designed and tested to solve such joint location and scheduling problems in cross-docking environments. 


\subsection{Internal operation planning}

Concerning internal operation planning, three strongly linked main subjects have received important attention in current research: truck scheduling, dock-door assignment and shopfloor operation scheduling.

Li et al. (2004) proposed a model to schedule internal operations based on a well-known parallel machines scheduling problem. At shop-floor, incoming containers are emptied and products are dispatched to the outbound area where outgoing containers are filled. Shop-floor teams are modelled as parallel machines which perform jobs (container loading). Storage is allowed if all machines are busy. The model seeks to minimize the sum of holding costs and penalty costs associated to earliness and tardiness, by defining the inbound and outbound container sequence. A set of heuristics is proposed and compared to an exact method. Results demonstrated that the heuristics provide good solutions in terms of costs and computing time.

Yu and Egbelu (2008) studied a cross-docking centre in which the transfer of products at shop-floor is performed by a conveyor belt. A storage area is considered. The authors propose several models to allocate products to outbound trucks and to determine truck sequence at dock-doors. A mathematical modelling approach, a complete enumeration method and a heuristic are developed and tested on randomly-generated instances of different sizes.

Truck scheduling at a cross-dock with a zero inventory policy is studied by Boysen (2010). A completely synchronised inbound and outbound truck schedule is mandatory. They identify three minimization objectives: total flow time, outbound trucks' processing time and tardiness (concerning shipping due dates) and their approaches treat one at time. An exact method based on dynamic programming and a heuristic based on simulated annealing are developed. 
Carrera et al. (2008) considered a negotiation model for planning and scheduling at a shoes distribution logistics platform. They propose an integer linear programming model to smooth workload by modifying the dates of arrival (from suppliers) and departure (to costumers). Storage capacity constraints, earliness and tardiness costs and inventory holding costs are considered. The model is implemented and tested with CPLEX, using generated data based on two industrial propositions.

A case study at Kodak cross-dock platform is exposed by Palmer (2005). They evaluate the impact of cross-docking level loading on the overall supply chain costs. According to the author, detailed analyses based on distribution network characteristics are required in order to evaluate the trade-offs between inventory policies, service level, transportation costs and workforce size.

Ladier et al. (2014) proposed a sequential approach to deal simultaneously with weekly planning and daily rostering of workforce in a logistics platform. To do so, they develop and implement in CPLEX three different mixed-integer linear programs. Industrial data is used for computational experiments and regarding the quality of solutions, the proposed models were adopted by their industrial partner.

Described studies on distribution planning and shipment consolidation presented above could be applied in a single cross-docking network. The reduction of transportation and storage costs is a common objective; however, it seems that ILN characteristics are not jointly represented in any current work. For instance, Chen et al. (2006) and Miao et al. (2009) do not include transportation units, as they consider product shipments as flows. Modelling presented by Gümüs and Bookbinder (2004) and Musa et al. (2010) do not allow storage at 
the cross-dock. Moreover, current research on distribution planning does not include shopfloor activities, such us internal flows, repacking activity or workload assessment. On the other hand, operational models do not take into account inbound and outbound transportation costs, but are focused on truck scheduling and package moving activities at shop-floor.

\subsection{Cross-dock scheduling}

Zheng et al. (2020) addresses the cold-chain cross-docking truck scheduling problem with two types of products. A mixed-integer linear programming model is developed to minimise the total operational costs that consist of inbound truck arrival penalties for violating contracted time windows, product delivery tardiness penalties, inventory costs and outbound truck transportation costs. The problem is solved in two steps. At the first step, the inbound truck arrival schedule is calculated, then, at the second step, the schedule of outbound truck departure and internal processing schedule are optimized. Heuristics are proposed to generate complete solutions of the considered two-stage problem.

Sayed et al. (2020) have studied integrated cross-dock door assignment and truck scheduling problem to simultaneously determine the assignment and scheduling of incoming trucks to inbound doors and outgoing trucks to outbound doors, with the objective of minimizing the total time to process all trucks. Metaheuristics are proposed.

In (Serrano et al. 2017), it was examined a mixed integer linear programming model to schedule hour by hour inbound trucks' arrival times (considering given soft time windows), shop-floor repackaging operations and outbound trucks' departure times. Capacitated temporary storage zones and a capacitated repack workshop are considered at crossdock shopfloor. The model seeks to minimize penalty costs related to inbound trucks' arrival times and consequently unbalanced workload of the repack workshop. 
Most of problems studied in literature for cross-doc are scheduling problems. An exhaustive state of the art on cross-dock scheduling is presented in (Theophilus et al, 2019).

Finally, Kiani Mavi et al (2020) present a bibliometrics analysis of cross-dock problem and show than most of publications are dedicated to one of the following problems: vehicle routing, scheduling, inventory management and distribution management. The studies on joint analysis of all these problems are missing.

This research work seeks to establish a link between tactical and operational planning decisions in cross-docking by proposing a distribution planning model that includes shopfloor planning decisions. In contrast to the vast literature in cross-dock optimization where these problems are considered independently, integration and interactions issues taking into account the dependency between them are crucial (Dauzère-Pérès and Lasserre, 2002; Dolgui and Proth, 2010; Kumar et al., 2020). This work follows the previous publication (Serrano et al., 2017) and both of them represent a new two-step approach (planning and scheduling) for Renault ILN platforms.

Instead of searching for rule based heuristics, as in majority of existing publications, in this paper, an integer linear program is developed and the commercial solver CPLEX is used to solve it. The advantage is in the possibility to obtain exact optimal solutions and if, at the end of calculation time, the formal proofs of optimality of the best obtained solutions are not terminated by CPLEX, the best solutions obtained are always near to optimum (or even optimal). Therefore, this approach is very practical and perfectly adapted to real life problems as it is demonstrated in the rest of the article.

\section{MODELLING AND NUMERICAL EXPERIMENTS}




\subsection{Problem description}

A model to combine the distribution and the operation planning at a cross-dock centre is proposed. For a given week, the model seeks to define the daily activities on the inbound, inside of ILN and on the outbound. The main input data is: the daily customer demand, the inbound vehicles capacities, the staging zones capacities, an inbound transportation precontracted plan, the shop-floor processing time per component and all related costs including resource costs (operators, etc.). As a planning model, the granularity considered is the day and, as a consequence, the truck scheduling decisions (time slot, assignment to doors, ...) are outside of the scope of this paper (see Serrano et al., 2017, for a description of the subsequent scheduling model used for these decisions). The details on the modelling are given below.

For the distribution planning problem, a single-cross-docking network is considered, with a set of suppliers upstream and a set of customers downstream. Decision variables are related to the component flows within the network and by extension, the number of inbound trucks and outbound containers. As exposed in section 3, few researches on the field consider transportation units. The approximation on the number of vehicles is based on packages dimensions and a cargo loading software is used to evaluate its performance. The latter is detailed in section 4. Particular constraints related to the pre-contracted inbound transportation plan include daily time windows, number of pre-contracted vehicles and penalty costs of cancelling a pre-contracted vehicle or contracting an extra one. Finally, in terms of costs, the model seeks to minimize the total cost composed of inbound transportation costs, linked to the number of trucks and penalty costs, and the outbound transportation costs, based on the number of containers as well as resource costs. This structure of total cost was validated by Renault, taking into account the specificity of their ILNs. 
Two main aspects are included to model the shop-floor internal operation. The first one is the workload level induced by package unloading from inbound trucks, component repacking at the workshop (if needed) and package loading into outbound containers. The resulting workload level defines the needs on internal resources needs for the whole week. The second aspect is the storage level at the staging zones. An unlimited capacity (storage/space) for the repacking workshop is considered. In contrast, a limited total capacity is assumed for both inbound and outbound staging areas. The proposed configuration implies that package flow, at the shop-floor, is load-driven since components can be retained in order to improve the container filling rate.

The previous descriptions imply the existence of an important link between the distribution planning decisions and the operation planning decisions. For instance, inbound trucks' arrival schedule defines the unloading workload at the shop-floor and the mix of components impacts the repacking workshop activity. Moreover, the availability of components at the shop-floor, for each final customer, will affect the outbound container loading activity and the storage decisions. The described relationship among tactical and operational levels supports our proposal of a joint model.

\subsection{Mathematical formulation}

For the problem considered with all given assumptions which are specific for Renault ILNs, the following model was developed in this study. This is an integer linear program (integer decision variables and linear objective function and constraints), thus, it can be solved to prove the optimality of the decisions obtained (Nemhauser and Wolsey, 1998) which is a clear advantage with respect to the heuristics usually used in literature.

The proposed model uses the following notation:

Sets: 
$i$ in $I \quad$ Components

$d$ in $D \quad$ Days of the week $[1,5]$

$c$ in $C \quad$ Customers

$s$ in $S \quad$ Suppliers

Parameters:

$v_{i} \quad$ Volume $\left(\mathrm{m}^{3}\right)$ of component $i$.

$q_{i, d} \quad$ Demand of component $i$ on day $d$ (delivery schedule from current planning process).

$i t_{i, s} \quad 1$ if component $i$ is provided by supplier $s, 0$ otherwise. Where $\sum_{s} i t_{i, s}=1 \forall i$.

$\operatorname{od}_{i, c} \quad 1$ if component $i$ is demanded by customer $c, 0$ otherwise. Where $\sum_{c} \operatorname{od}_{i, c}=1 \forall i$.

$p v_{d, s} \quad$ Number of contracted vehicles in day $d$, for supplier $s$.

$u t_{i} \quad$ Unloading time of component $i$.

$r t_{i} \quad$ Repackaging time of component $i$.

$l t_{i} \quad$ Loading time of component $i$.

$w d_{d} \quad 1$ if $\mathrm{d}$ is a working day, 0 otherwise.

wh Worked hours per day.

vit Maximum capacity $\left(\mathrm{m}^{3}\right)$ of inbound trips (per vehicle).

voc Maximum capacity $\left(\mathrm{m}^{3}\right)$ of outbound containers (per container).

voz Maximum capacity of the outbound staging zone $\left(\mathrm{m}^{3}\right)$

cit $_{s} \quad$ Fixed cost of a contracted vehicle for inbound trip $s$.

cc Cancellation cost (ratio) of a contracted vehicle.

cev Extra cost (ratio) of contracting an extra vehicle.

cst $\quad$ Storage cost per $\mathrm{m}^{3}$ and per day.

cwf Internal resource cost per unit (salary cost of one operator, for example).

$\cot _{c} \quad$ Fixed cost of a container for outbound destination $c$ (the cost which does not depend on the content of a container, it covers the cost of transportation of the container to the destination $c$, i.e. plant $c$ ). 
$d s \quad 1$ if delivery schedule from current planning process must be respected, 0 otherwise.

Decision variables:

$X_{i, d} \quad$ Incoming quantity of component $i$ on day $d$.

$Y_{i, d} \quad$ Outgoing quantity of component $i$ on day $d$.

$I T_{d, s} \quad$ Approximation of the number of contracted vehicles used for trip $s$ on day $d$.

$I T S_{d, s}$ Approximation of the number of extra vehicles used by trip $s$ on day $d$.

$O T_{d, c}$ Approximation of the number of containers used for destination $c$ on day $d$.

W Number of weekly internal resources (e.g. operators).

$S_{i, d} \quad$ Quantity of component $i$ stored on day $d$.

$\operatorname{Min} Z=I T \_c o s t+I A \_c o s t+O T \_c o s t$

where:

$I T_{-} \operatorname{cost}=\sum_{d, s}\left[c i t_{s} \times\left(I T_{d, s}+I T S_{\mathrm{d}, \mathrm{s}} \times c e v+w d_{d} \times\left(\mathrm{pv}_{\mathrm{d}, \mathrm{s}}-I T_{\mathrm{d}, \mathrm{s}}\right) \times \mathrm{cc}\right)\right]$

IA_cost $=W \times \mathrm{cwf}+\sum_{\mathrm{i}, \mathrm{d}}\left(S_{\mathrm{i}, \mathrm{d}} \times \mathrm{v}_{\mathrm{i}} \times \mathrm{cst}\right)$

OT_cost $=\sum \sum_{\mathrm{d}, \mathrm{c}}\left(O T_{\mathrm{d}, \mathrm{c}} \times \cot _{\mathrm{c}}\right)$

Subject to:

$\sum_{d} X_{i, d}=\sum_{d} q_{i, d}$

$\sum_{d} Y_{i, d}=\sum_{d} q_{i, d} \quad \forall i$

$X_{i, d} \leq \sum d^{\prime} q_{i, d^{\prime}} \times w d_{d} \quad \forall i, d$

$Y_{\mathrm{i}, \mathrm{d}} \leq \sum d^{\prime} q_{i, d^{\prime}} \times w d_{d}$

$\sum_{i} X_{i, d} * i t_{i, s} \times v_{i} \leq\left(I T_{\mathrm{d}, \mathrm{s}}+I T S_{\mathrm{d}, \mathrm{s}}\right) \times v i t \quad \forall d, s$

$\sum_{\mathrm{i}} Y_{i, d} \times o d_{i, c} \times v_{i} \leq O T_{\mathrm{d}, \mathrm{c}} \times v o c \quad \forall d, c$ 


$$
\begin{array}{ll}
I T_{d, s} \leq p v_{d, s} & \forall d, s \\
S_{i, 1}=X_{i, 1}-Y_{i, 1} & \forall i \\
S_{i, d}=S_{i, d-1}+X_{i, d}-Y_{i, d} & \forall i, d>1 \\
\sum_{i}\left(S_{i, d} \times v_{i}\right) \leq v o z & \forall d \\
\sum_{i}\left(X_{i, d} \times\left(u t_{i}+r t_{i}\right)+Y_{i, d} \times l t_{i}\right) / w h \leq W & \forall d \\
q_{i, d} \times d s \leq X_{i, d} & \forall i, d \\
X_{i, d} \in \mathbb{N}, Y_{i, d} \in \mathbb{N}, S_{i, d} \in \mathbb{N}, W \in \mathbb{N} & \forall i, d \\
I T_{d, s} \in \mathbb{N}, I T S_{d, s} \in \mathbb{N}, O T_{d, c} \in \mathbb{N} & \forall d, c, s
\end{array}
$$

Figure 4 illustrates the defined model. The objective function in (1) seeks to minimize total cost. Equation (2) represents the inbound transportation costs, which includes the number of trucks, as well as penalty costs generated by cancelled and additional trucks, (3) characterizes internal activity costs, defined by storage costs and operator (or another resource) costs. Equation (4) represents the outbound transportation costs, based on the number of containers used. Constraints (5) and (6) guarantee total demand fulfilment, (7) and (8) ensures the respect of working calendar, (9) and (10) represent, respectively, the inbound and outbound vehicle capacity and (11) denotes the number of pre-contracted inbound vehicles. Equations (12) and (13) are storage balance constraints that implies the inventory level of a component is equal to its previous inventory level in addition to the received quantity minus the shipped quantity in the current period (assuming that initial storage is zero). Equation (14) represents the outbound staging zone capacity, (15) assesses the resource needs for the week: it corresponds to the higher workload level. Constraint (16) will permit, if parameter ds $=1$, to respect the delivery schedule generated by the current planning software. Finally, (17) and (18) are integer constraints. 


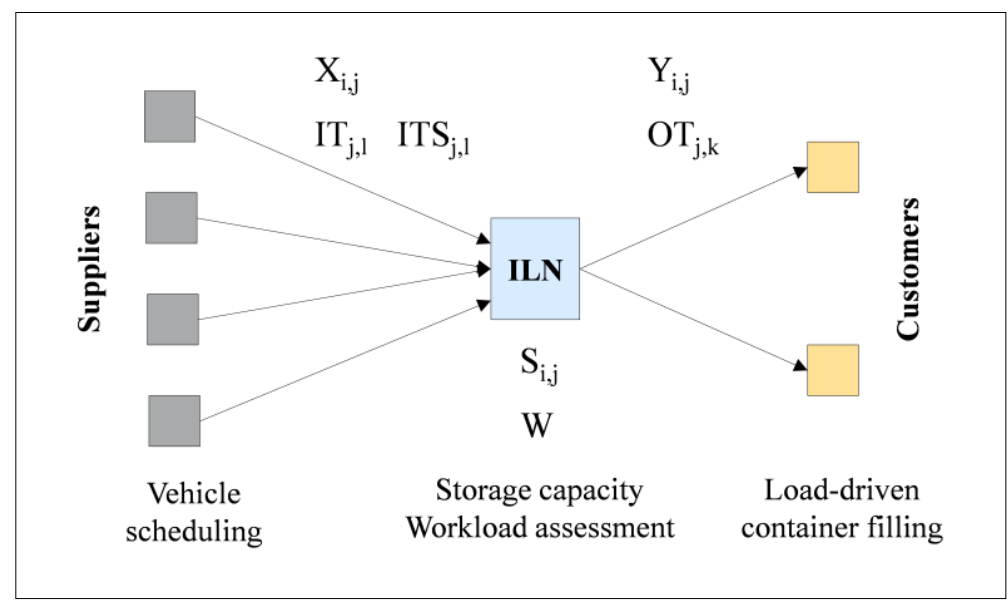

Figure 4. Proposed model scheme.

\subsection{Numerical experiments}

The model presented above was implemented and tested in CPLEX, using a 4GB RAM Intel Celeron P4600 @2.00GHz CPU. Table 2 summarizes the general statistics of the experiments, based on a 21-week period of real data from the Renault case of study. Some details are provided next: (1) an aggregation process, based on physical characteristics of components, was applied to group components (i.e. to consider similar components as identical). This process permitted to reduce, in average, $30 \%$ the total size of the input data. (2) Concerning the inbound transport for Renault ILNs there are two main types of trips: a) direct from supplier to ILN platform, and b) indirect, from supplier to a 3PL (third-party logistics) grouping platform, then to ILN. Both types are considered in the model. The first one represents $15 \%$ of Renault suppliers which account for $60 \%$ of total volume. Hence $85 \%$ of suppliers are in indirect transportation (40\% of total volume). (3) Finally, no modifications were done regarding final customers.

Figure 5 explains the methodology adopted for the experiments. For each week, two runs were made, with a calculation time limit of three minutes.

The first run simulates the current planning process at Renault ILN: (1) parameter $d s$ is set at 1 so that the original delivery schedule is respected, and (2), as explained in section 2.4, shop- 
floor operation is driven mainly by container filling performance rather than the daily shipment schedule and therefore the model assumptions for the rest of activities are aligned with the Renault ILN current planning algorithm. For the case $d s=1$, the calculation time of 3' is sufficient to obtain optimal solutions for the simplified model based on the current Renault planning software rules. If $d s=1$, many decision variables of the model (1) - (18) are fixed at the values obtained by Renault planning software, and so the model is simplified and solved to optimality $(\mathrm{gap}=0)$ for all weeks.

\begin{tabular}{|r|r|r|r|r|r|r|}
\hline $\begin{array}{c}\text { Week } \\
(\mathbf{n})\end{array}$ & $\begin{array}{c}\text { Components } \\
\text { (i) }\end{array}$ & $\begin{array}{c}\text { Suppliers } \\
\text { (l) }\end{array}$ & $\begin{array}{c}\text { Customers } \\
(\mathbf{k})\end{array}$ & Variables & Constraints & $\begin{array}{c}\text { Gap after 3' } \\
\boldsymbol{d} \mathbf{s}=\mathbf{0}\end{array}$ \\
\hline 1 & 1032 & 27 & 10 & 15801 & 38835 & 1.18 \\
\hline 2 & 1092 & 27 & 9 & 16396 & 41045 & 0.34 \\
\hline 3 & 1344 & 28 & 14 & 18951 & 50439 & 1.47 \\
\hline 4 & 1303 & 27 & 12 & 18521 & 48882 & 2.07 \\
\hline 5 & 1096 & 26 & 15 & 16456 & 41233 & 1.23 \\
\hline 6 & 915 & 28 & 15 & 14666 & 34576 & 0.87 \\
\hline 7 & 668 & 26 & 12 & 12161 & 25367 & 0.11 \\
\hline 8 & 693 & 25 & 18 & 12431 & 26332 & 0.80 \\
\hline 9 & 813 & 25 & 12 & 13601 & 30712 & 0.18 \\
\hline 10 & 1354 & 28 & 16 & 19061 & 50829 & 1.15 \\
\hline 11 & 1278 & 28 & 15 & 18296 & 48007 & 1.30 \\
\hline 12 & 1229 & 28 & 15 & 17806 & 46194 & 1.27 \\
\hline 13 & 1298 & 28 & 15 & 18496 & 48747 & 0.37 \\
\hline 14 & 1397 & 28 & 14 & 19481 & 52400 & 1.44 \\
\hline 15 & 1437 & 28 & 16 & 19891 & 53900 & 0.67 \\
\hline 16 & 1469 & 28 & 16 & 20211 & 55084 & 1.51 \\
\hline 17 & 1507 & 28 & 17 & 20596 & 56500 & 2.98 \\
\hline 18 & 1325 & 27 & 17 & 18766 & 49746 & 1.88 \\
\hline 19 & 1402 & 28 & 16 & 19541 & 52605 & 2.88 \\
\hline 20 & 1396 & 28 & 15 & 19476 & 52373 & 1.47 \\
\hline 21 & 1422 & 28 & 15 & 19736 & 53335 & 1.75 \\
\hline
\end{tabular}

Table 2. Numerical experiments statistics

In the second experimental run, parameter $d s$ is set at 0 and hence the entire developed model is used to propose an optimal planning concerning both delivery and shipment schedules without taking into account the Renault planning software decisions. Considering the dimensions of problems, the theoretical optimality of solutions for the considered cases, was not proved, thus this is a gap which is the difference between the best solution obtained and the theoretical lower bound calculated by the solver (see table 2). 
Inbound transportation, internal resources and outbound transportation costs are assessed for each week and for both experimental runs.

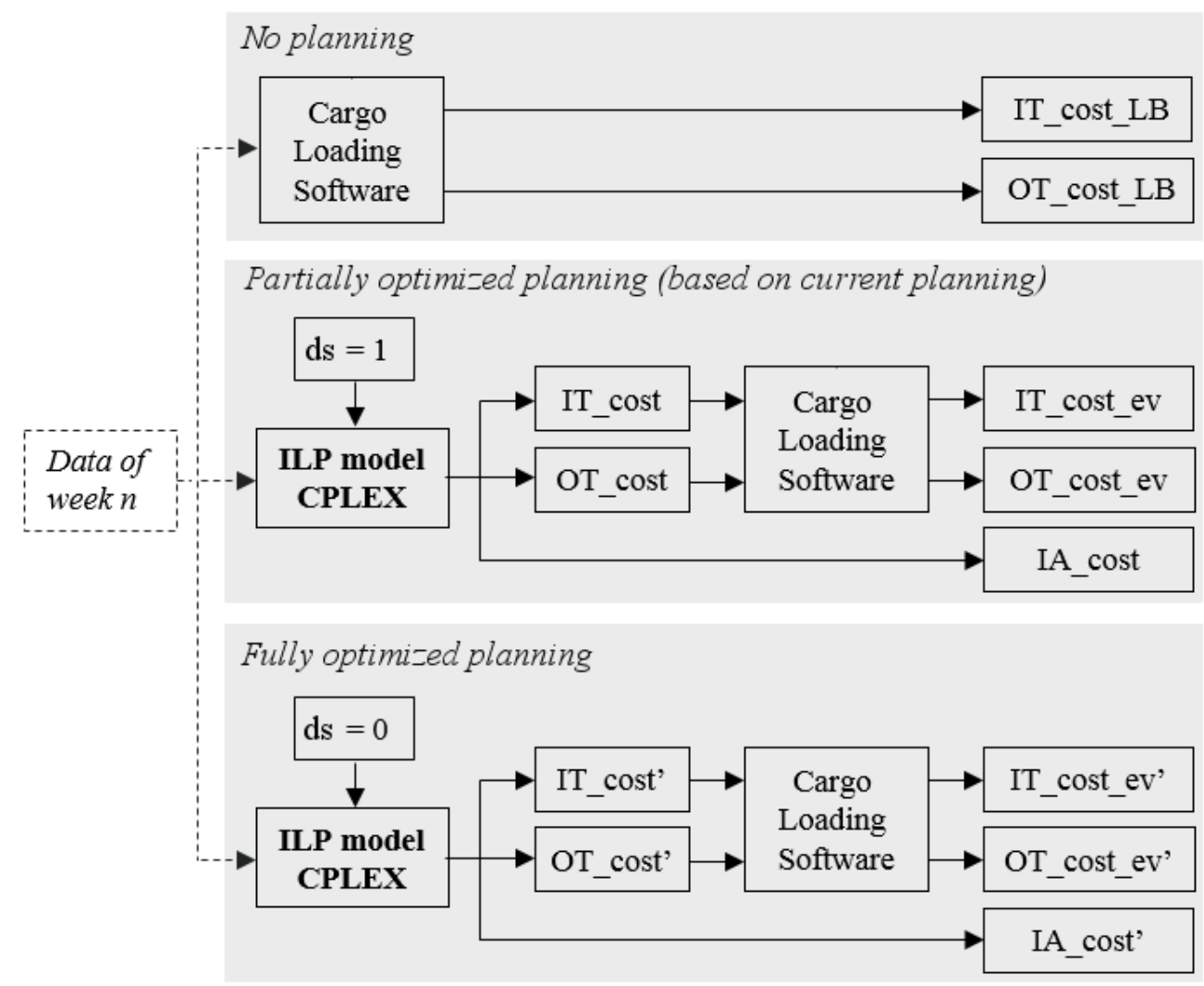

Figure 5. Numerical experiments methodology.

Since the optimisation model provides an approximation on the number of vehicles (inbound and outbound), CPLEX results were also compared with those obtained with a cargo loading software developed by Renault. In the next section the performance of the optimisation model is evaluated and analysed. In figure 5, three planning approaches are explained: No planning is the situation in Renault before the study considered; Partially optimized planning is the case when the proposed model is only partially used to be compatible with the decisions of No planning approach (some variables are fixed at the values given by the Cargo loading software); and finally, the case of Fully optimized planning when the entire model is used without limitations from Cargo loading software.

\subsection{Performance analysis}


On average, the proposed model showed a total cost reduction of $13 \%$ ( $d s=0$ vs $d s=1)$. More accurate conclusions can be drawn by analysing individually each cost driver. Figure 6(a) compares the inbound transportation costs. First, it is observed that the current planning process (IT_cost_ev) gives the results which are 28\% above the lower bound (IT_cost_LB) on average, that estimates the potential profit. Second, it is observed that CPLEX result(IT_cost') is equivalent to the lower bound. However, once evaluated by the cargo software (IT_cost_ev'), the difference between both costs (IT_cost_ev' and IT_cost_LB) is around $11 \%$. The latter can be explained by the fact that the cargo software was developed exclusively for truck load maximisation and includes very complex and detailed constraints, in terms of type of package combination and stacking rules, among others. The model proposed in this paper cover larger scope but gives a much simpler approximation on the number of inbound trucks. Finally, by comparing evaluated inbound transportation costs obtained with both models, it can be concluded that the model proposed in this paper outperforms the current planning process in $17 \%$ (average per week, with a standard deviation of 4.7). The relative values of costs are given in figure 6 (due to the confidentiality issue it is not possible to present the corresponding absolute values). The outbound costs were constant; thus they are not reported in the figure. The minimum level of costs in the figure (as in figure 7) is zero. 


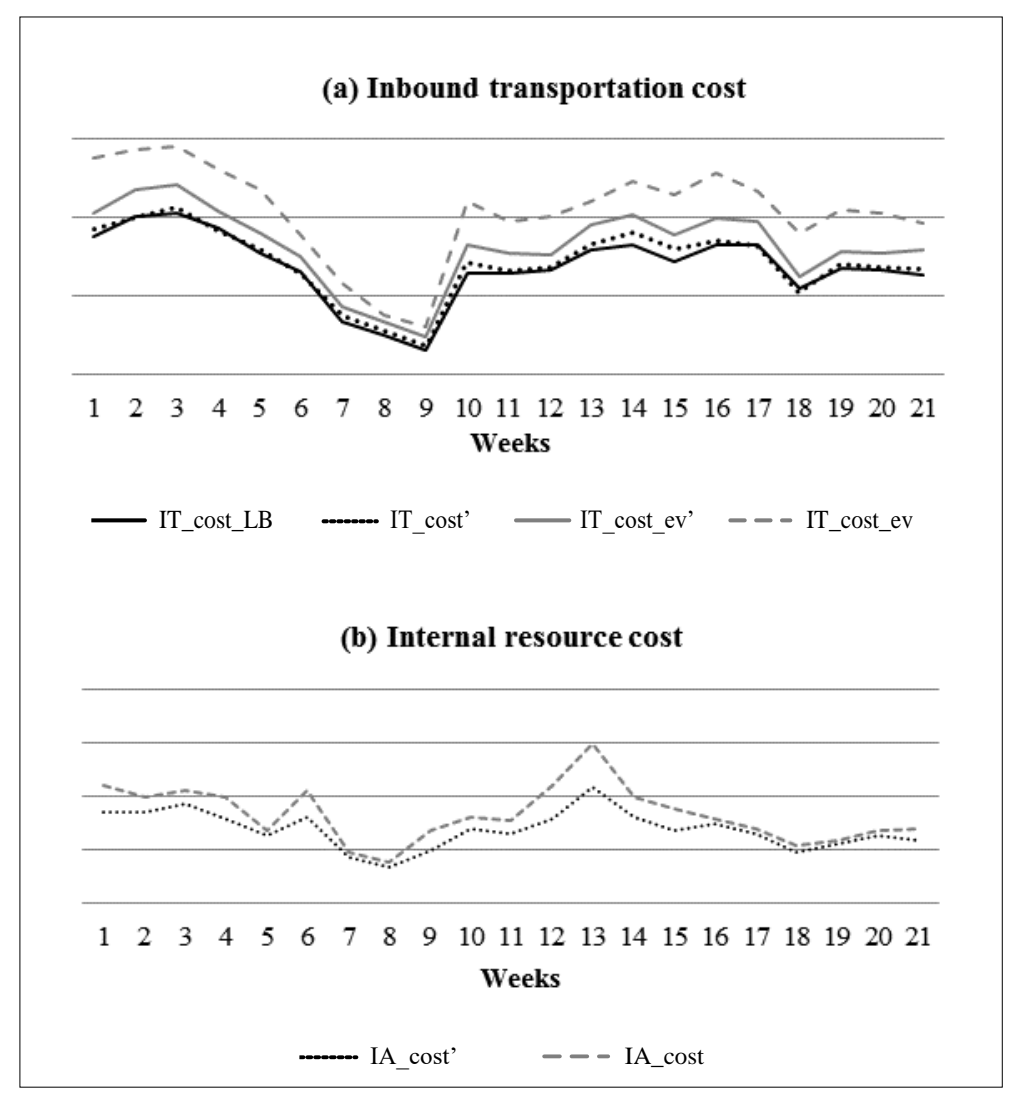

Figure 6. Relative values from numerical experiments.

The second cost driver is the internal activity (IA_cost). As specified before, there are two components related to internal activity: storage and resources. Numerical experiments showed that average storage level per week can drop from $30 \%$ in the current planning method to less than $1 \%$ with the proposed model. At this point of our work, storage costs have not been sharply defined and that is why the model performance was analysed in terms of storage level rather than costs. Figure 6(b) compares resource (e.g. operator) costs. These costs are associated to daily workload peaks, and regarding the current planning process, this effect is more strenuously marked in weeks with public holidays (e.g. weeks 6, 12, 13). In 5-labor-day weeks the proposed model shows an average cost reduction of $13 \%$ with a standard deviation of 6.3. An important consequence of internal resources optimization is daily workload smoothing for each shop-floor activity (unloading, repackaging and loading), which will translate into a better organisation and management of ILN internal operations. Finally, 
outbound transportation costs are alike in both original and proposed planning process. This is the consequence of the outbound load-driven configuration combined with the possibility of storage in the outbound staging zone.

\section{INDUSTRIAL IMPLEMENTATION}

In real-life context, only a simplified version of the model concerning inbound transportation was implemented and used, because, on the one hand, the results of numerical simulations showed a significant potential on cost reduction in this segment (inbound transportation) and thus, for Renault, this was a priority, and on the other hand, because from an industrial point of view, the modification of the delivery schedule is a conceivable process and can be easily integrated in the existing software employed by Renault, that is not the case for the rest of model. The simplified version, compared to the model presented in section 4, kept only decision variables related to inbound transportation: $(X, I T, I T S)$. Consequently, the objective function concerns only inbound transportation cost (IT_cost) and the constraints (6), (8), (10), (12) - (15) were excluded. The outbound transport is guided by availability of container and vehicles; taking into account the limited numbers of vehicles the transportations are done in a smooth manner. The optimisation of the inbound part did not increase the outbound stocks and costs.

A group of suppliers, representing in average $15 \%$ of total weekly volume, was selected for the industrial full-scale test with Renault software. For the concerned scope, the delivery schedule was calculated using the proposed method and afterwards it was incorporated to the Renault information system. The outline is that the delivery orders transmitted to suppliers correspond to the optimized planning generated by the model. 
Figure 7 shows the obtained results during a 15-week test. As in figure 6, only relative values are represented. The same methodology from numerical experiments was used and hence both evaluated costs (IT_cost_ev and IT_cost_ev') were compared. Based on the previous offline tests, the expected total cost reduction was $26 \%$. By analysing physical deliveries at ILN, the real inbound transportation costs (IT_cost_REAL) were calculated to asses the performance of the tests: it was observed that, for studied suppliers, inbound transportation costs were reduced by $20 \%$.

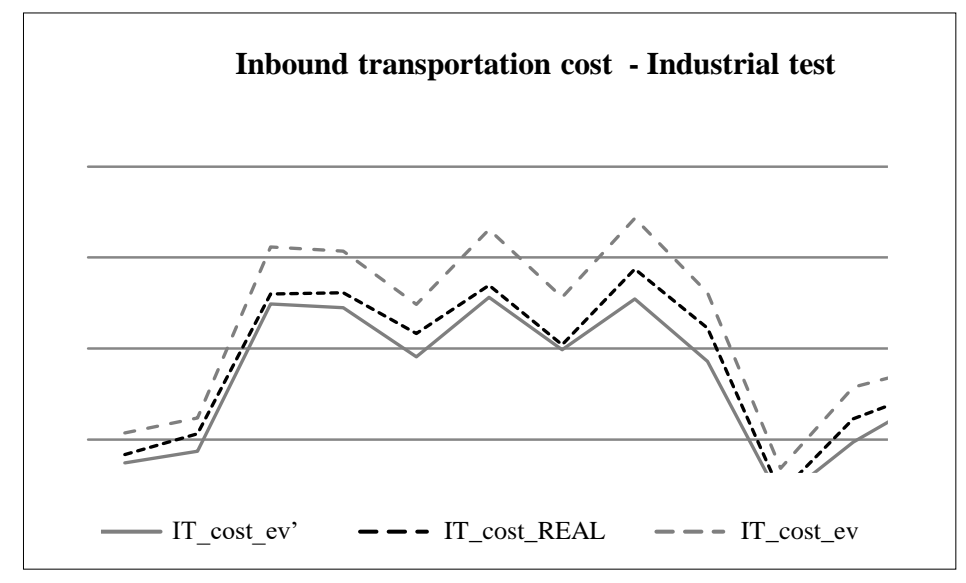

Figure 7. Relative costs evolution over weeks.

The difference between expected planning (IT_cost_ev') and real performance (IT_cost_REAL) can be explained on the one hand, by a non-accurate approximation of the number of vehicles in the optimisation model and on the other hand, by external factors such as transportation delay, supplier's capacity, etc. Further analysis is needed in order to cope with described issues.

\section{OPEN ISSUES FOR GENERALISATION}

This is the first stage of an extended optimization project concerning planning processes at Renault cross-dock platforms. First of all, concerning strategic issues, even if they are out of scope at this point, the following research perspective should be considered: it might be interesting to include tactical or even operational characteristics in strategic analysis. For 
instance, for the geographic location, all cost drivers must be taken into account: even if the outbound transportation costs reduction seems high, the inbound transportation management might be relatively expensive. The shop-floor layout can be impacted by the transit time, which on its own, can be affected by the diversity of packages and the complexity of outbound trucks loading activity. So, it is necessary to include this kind of aspects when deciding the set-up of a cross-dock centre. Even if this seems to be far away from the presented study, this point is now discussed with Renault for future projects.

The presented work was focused on the tactical and the operational levels. It was concluded that it was necessary to link both decisional levels in order to obtain a better synchronization between the three segments of the logistics network within a cross-dock platform and for that the cost drivers for the inbound, internal and outbound activities were included in the study. Even though the modelling approach was based on a case of study, it remains relatively generic and can be adapted to other cross-dock platforms and configurations, because the main elements of any platform were considered and the model was proposed after considering several platforms and tested on one of them.

An extension of our field study to other platforms, showed on the one hand, that the three main cost drivers originally identified (inbound, internal and outbound) are found in other Renault ILN. On the other hand, we saw that both the physical flows and the cost distribution can vary between Renault cross-dock platforms. In the next paragraphs we explain the main differences and how our model can be adapted to respond to different characteristics.

In the inbound segment, one can think that the platform is not responsible for organizing the transportation, which means that the number of trucks is not the accurate cost driver. In order to adapt the presented model, inbound decision variables should be slightly modified: for 
instance, instead of an approximation on the number of trucks, a fixed cost (related to each order) and a variable cost (related to the volume of the order) would define the inbound cost. Concerning the internal activity, regarding the type of products, there are some cross-dock centres that do not have temporary staging zones (for instance, in the food industry) and packages are directly moved to the outbound zone. The latter is not an issue, since the presented model can run without an inbound staging zone.

Regarding internal cost configuration, we have seen that the physical operation can be performed by a 3PL provider. Same for the inbound variables, an adaptation of the model will be needed. The new internal cost driver could be the daily volume and a constraint related to the maximum capacity per day could be added. Finally, on the outbound segment there can be different patterns in terms of transportation frequency. In fact, other than customers on overseas transportation (one cargo ship per week), the cross-dock can ship containers by truck or train, for which the frequency can reach the daily basis. Our model should be adapted to include this constraint, which is translated on customer time windows for the concerned components.

The industrial case study also showed that the container loading activity is a very complex task due to a high diversity on package dimensions and stacking rules. The approximation of number of trucks made in the proposed model results in good solutions for integrated planning at the tactical and operational levels. However, for a shop-floor scheduling, a deeper approximation of number of vehicles will be definitely necessary and will be a future research perspective. A possible approach consists in integrating the cargo loading software solutions into the proposed model. 
Another relevant inference from this study is that it might be necessary to assess the impact of environmental factors, such us transportation delay and supply capacity issues. The shop-floor operation planning could also be improved by adding some industrial constraints, such as the capacity of the repacking workshop and a better assessment of the storage capacity and costs.

\section{CONCLUSIONS}

Overseas cross-dock platforms play a key role in the automotive supply chain. They connect distant industrial sites with first-tier suppliers, enhancing economies in transportation and simplifying overseas procurement management. This work was based on the real life techniques used at Renault for the distribution and operation planning, key activities to assure the performance of the network.

The work presented in this paper follows an operational model in the previous article (Serrano et al., 2017) where scheduling issues with limited capacities were considered. This two-stage approach (planning and scheduling) was developed and tested for a Renault ILN platform, but can be extended to other cross-docks.

In this paper, a case study at Renault was presented for the planning part, including the current planning method and a field study at one of the Renault ILN platforms. Accordingly, an alternative planning approach to reduce total cost was developed. The cross-dock network was modelled as an integer linear program integrating inbound, internal and outbound constraints. Both, tactical decisions on distribution planning and operational decisions on shop-floor activities are addressed in the model. The model was implemented and tested with CPLEX for a 21-week period of industrial data from one of the Renault ILNs. In order to get a more precise assessment of transportation costs, a cargo loading software was employed and a performance analysis was conducted based on its results. 
The proposed model outperformed the current method employed at Renault, reducing total costs by $13 \%$. Each cost driver was analysed individually, finding an important profit potential on inbound transportation and internal activity costs. Outbound transportation costs remain constant. An industrial implementation of a simplified version of the model was tested during 15 weeks. It concerned only the inbound transportation part and it was observed a cost reduction of $20 \%$ for the reduced group of suppliers integrated in the test. Results allow to: (1) validate the pertinence of the proposed model, (2) corroborate the gap between the model's approximation on the number of vehicles and reality and (3) notice the influence of external factors on the expected performance. Deeper analysis is needed to better assess items 2 and 3.

The case study presented in this paper reveals, on the one hand, that tactical and operational decisions at a cross-dock are strongly correlated; hence, research on models tackling jointly both decisional levels seems crucial to assure an optimal performance. On the other hand, results on numerical experiments and industrial implementation showed that the proposed approach provides performant solutions for distribution and operation planning. The main contribution of this paper relays on treating jointly two fields related to cross-docking, which are for most cases, apprehended individually.

\section{REFERENCES}

Agustina, D., Lee, C., Piplani, R., 2014. Vehicle scheduling and routing at a cross docking centre for food supply chains. International Journal of Production Economics, 152, 29-41.

Bienert, G., Kornfeld, B., Kara, S. 2017. Delivery lot splitting as an enabler for cross docking and fast delivery. Procedia CIRP, 63, 639-644. 
Boysen, N., 2010. Truck scheduling at zero-inventory cross docking terminals. Computers \& Operations Research, 37 (1), 32-41.

Boysen, N., Fliedner, M., 2010. Cross dock scheduling: Classification, literature review and research agenda. Omega, 38 (6), 413-422.

Carbone, V., De Martino, M., 2003. The changing role of ports in supply-chain management: an empirical analysis. Maritime Policy \& Management, 30 (4), 305-320.

Carrera, S., Chami, K., Guimaraes, R., Portmann M-C., Ramdane-Cherif, W., 2008. Negotiation models for logistic platform planning and scheduling. 11th International Workshop on Project Management and Scheduling, Istanbul, Turkey, 43-46.

Cârstea, V., 2013. Delocalization - the automotive industry's answer to cost reduction. Romanian Economic Business Review, 8 (3.1), 180-183.

Chen, P., Guo, Y., Lim, A., Rodrigues, B., 2006. Multiple cross-docks with inventory and time windows. Computers \& Operations Research, 33(1), 43-63.

Dauzère-Pérès, S., Lasserre, J-B., 2002. On the importance of sequencing decisions in production planning and scheduling. International Transactions in Operational Research, $9(6), 779-793$.

Dolgui, A., Proth, J.-M., 2010. Supply chain engineering: Useful methods and techniques, Springer.

Fleischmann, B., Ferber, S. \& Henrich, P. 2006. Strategic planning of BMW's global production network, Interfaces, 36(3), 194-208.

Frigant, V., Martin, Z., 2014. Are automotive global production networks becoming more global? Comparison of regional and global integration processes based on auto parts trade data. [Available at: http://cahiersdugretha.u-bordeaux4.fr/2014/2014-09.pdf].

Gümüs, M., Bookbinder, J. H., 2004. Cross-docking and its implications in locationdistribution systems. Journal of Business Logistics, 25 (2), 199-228. 
Itoh, I., Guerrero, D., 2020. Investigating variations in the deep-sea sourcing strategies of car manufacturers: Two case studies of parts consolidation centers in Japan, Case Studies on Transport Policy, 8 (2), 293-299.

Kiani Mavi, R., Goh, M., Kiani Mavi, N., Jie, F., Brown, K., Biermann, S., Khanfar, A., 2020. Cross-Docking: A Systematic Literature Review, Sustainability, 12, 4789.

Kumar S., Manjrekar V., Singh V., Kumar Lad B., 2020. Integrated yet distributed operations planning approach: A next generation manufacturing planning system, Journal of Manufacturing Systems, 54, 103-122.

Ladier, A.-L., Alpan, G., 2016. Cross-docking operations: Current research versus industry practice. Omega, 62, 145-162.

Ladier, A-L., Alpan, G., Bernard, P., 2014. Joint employee weekly timetabling and daily rostering: A decision-support tool for a logistics platform. European Journal of Operational Research, 234 (1), 278-291.

Li, Y., Lim, A. Rodrigues, B, 2004. Crossdocking: JIT Scheduling with Time Windows. The Journal of the Operational Research Society, 55 (12), 1342-1351.

Li, Z., He, W., Sim, C. H., Chen, C., 2008. A solution for cross-docking operations planning, scheduling and coordination. IEEE International Conference on Service Operations and Logistics, and Informatics, Beijing, China, 2, 2957-2962.

Ma, H., Miao, Z., Lim, A., Rodrigues, B., 2011. Crossdocking distribution networks with setup cost and time window constraint. Omega, 39 (1), 64-72.

Meysam Mousavi, S., Tavakkoli-Moghaddam R., 2013. A hybrid simulated annealing algorithm for location and routing scheduling problems with cross-docking in the supply chain. Journal of Manufacturing Systems, 32 (2), 335-347.

Miao, Z., Yang, F., Fu, K., 2009. Transhipment problem with penalty in crossdocking distribution networks. 6th International Conference on Service Systems and Service Management, Xiamen, China, 280-285. 
Musa, R., Arnaout, J-P., Jung, H., 2010. Ant colony optimization algorithm to solve for the transportation problem of cross-docking network. Computers \& Industrial Engineering, 59 (1), 85-92.

Nemhauser, G., Wolsey L. Integer and Combinatorial Optimization. Wiley, 1998.

Palmer, J., 2005. Level loading and cross-docking in a global logistics network. Master thesis, Sloan School of Management, Cambridge, United States. [Available at: http://dspace.mit.edu/handle/1721.1/34849].

Renault, 2016. Atlas Renault. [Available at: https://group.renault.com/wp-content/uploads/2016/03/atlas-2015_fr.pdf].

Sayed, S. I., Contreras, I., Diaz, J. A., Luna, D. E. 2020. Integrated cross-dock door assignment and truck scheduling with handling times, TOP, 28, 705-727.

Saddle Creek Logistics Services, 2011. Cross-docking trends report, [Available at: http://www.sclogistics.com/news-resources/white-papers/41-cross-docking-trends-report$\underline{1 / \text { file }] .}$

Serrano, C., 2017. Planification et ordonnancement des activités dans un centre de crossdock international, PhD Thesis, University of Lyon, France.

Serrano, C., Delorme X., Dolgui A., 2015. Distribution and operation planning at a crossdock platform: A case of study at Renault, 4th IEEE International Conference on Advanced Logistics and Transport, 193-198.

Serrano, C., Delorme X., Dolgui A., 2017. Scheduling of truck arrivals, truck departures and shop-floor operation in a cross-dock platform, based on trucks loading plans. International Journal of Production Economics, 194, 102-112.

Soleimaninanadegany, A., Hassan, A., Rahiminezhad Galankashi, M., 2017. Product allocation of warehousing and cross docking: a genetic algorithm approach. International Journal of Services and Operations Management, 27 (2), 239 - 261. 
Theophilus, O., Dulebenets, M.A., Pasha, J., Abioye, O.F., Kavoosi, M. 2019. Truck Scheduling at Cross-Docking Terminals: A Follow-Up State-Of-The-Art Review. Sustainability, 11, 5245.

Van Belle, J., Valckenaers, P., Cattrysse, D., 2012. Cross-docking: state of the art. Omega, 40 (6), 827-846.

Yu, W., Egbelu P. J., 2008. Scheduling of inbound and outbound trucks in cross docking systems with temporary storage. European Journal of Operational Research, 184 (1), 377396.

Zheng, F., Pang Y., Xu Y. \& Liu M., 2020. Heuristic algorithms for truck scheduling of cross-docking operations in cold-chain logistics, International Journal of Production Research, DOI: 10.1080/00207543.2020.1821118 